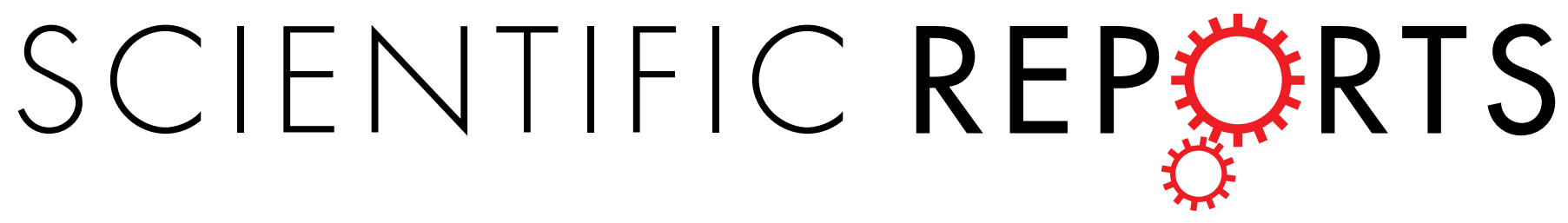

\title{
Erratum: Phosphorene nanoribbon as a promising candidate for thermoelectric applications
}

J. Zhang, H. J. Liu, L. Cheng, J. Wei, J. H. Liang, D. D. Fan, J. Shi, X. F. Tang \& Q. J. Zhang

Scientific Reports 4:6452; doi: 10.1038/srep06452; published online 23 September 2014; updated 10 July 2015

This Article contains typographical errors in Table 2. For 7-APNR (n-type) the $\kappa_{P}(\mathrm{~W} / \mathrm{mK})$ value ' 34.64 ' should read '0.67'. In addition, for $8-\mathrm{H}-\mathrm{ZPNR}$ (n-type) the $\kappa_{P}(\mathrm{~W} / \mathrm{mK}$ ) value '34.74' should read '34.64'. 